\title{
REVOLUÇÃO, REVELAÇÃO: UM DESENHO DA PINTOR(A)RTE À ESPERA, NA PEÇA $A$ SEMANA
}

\author{
Bruno Leal Piva ${ }^{1}$
}

\begin{abstract}
E se um dia ou uma noite um demônio se esgueirasse em tua mais solitária solidão e te dissesse: Esta vida, assim como tu vives agora e como a viveste, terás de vivê-la ainda uma vez e ainda inúmeras vezes: e não haverá nela nada de novo, cada dor e cada prazer e cada pensamento e suspiro e tudo o que há de indizivelmente pequeno e de grande em tua vida há de te retornar, e tudo na mesma ordem e sequência. (Nietzsche, 2005: 170, aforismo 341)
\end{abstract}

Aparentemente, acaso da ocasião. Assim aparece a personagem Pintora, acompanhada pela personagem ELE, em $A$ Semana $^{2}$. ELE a alicia, impede, se impõe, barra, castra, manda e desmanda. A personagem Carlos, um homem angustiado pela mesmice do dia a dia, tenta enfrentá-LO. Mas é a Pintora quem realmente põe fim a esse aprisionamento, que de tanto esperar, continua aprisionada. Quem seria essa Pintora? Quem estaria por trás dessa personagem que ansia por liberdade e encontra por si quem quer encontrá-la? E quem seria ELE, morto pela heroína derrotada em uma batalha, mas vencedora de uma guerra?

O que será? o que será? Talvez a questão do tempo. Mas, não! O tempo de Beckett é o de uma espera indeterminada; o da minha peça é o da precipitação acelerada num nada, talvez existencial ou pó-existencial... tudo converge ao longo de uma semana para uma meta-nada onde se sabe que ninguém efectivamente virá...enquanto que o Godot pode ainda chegar a qualquer momento... Bom, isso é já uma diferença consoladora... De facto, em A Semana assistimos ao trajecto de um optimismo lírico e ingénuo para um pessisimismo irremediável que talvez já não seja pessimismo mas um nada, um vazio intuído, igualmente lírico e ingénuo... e sem transcendência... sem transcendência?... (Castro, 2006: 17).

No contexto em que Luiz de Castro escreve essa obra, angustiado pela espera do devir de seu reconhecimento como autor e castrado pelo governo Salazarista de sua época, não seria difícil estabelecer uma conexão com sua personagem central, Carlos. O

\footnotetext{
${ }^{1}$ Universidade Nova de Lisboa, Portugal. Email: brulepi@gmail.com ORCID id: https://orcid.org/0000-0002-5145-8391

2 E.M. de Melo Castro (2006:35-62) adota Luiz de Castro como escritor dessa peça, datada em1954 e revista em 1958, e das demais peças do Teatro do Homem (L)ido.
} 
homem, na luta contra o próprio homem, na tentativa de combate travada contra a ganância estarrecedora pelo poder que Ele, Salazar, impõe contra sua arte.

ELE: Mas isto é inadmissível!...Assim não podemos trabalhar!

CARLOS: Você não tem nada com isto. Além disso quem pinta é a pintora, e não o senhor!

ELE: ...temos uma reputação profissional...

CARLOS: Quanto a mim você não tem nada porque não faz nada, senão inspeccionar... (Castro, 2006: 40).

Mas como poderia, Luiz (ou Carlos), vencer essa guerra, em busca de sua liberdade, senão pela própria arte?

No decorrer do texto dramatúrgico, é possível observar uma tentativa de ruptura contra a rotina, comodismo e conformismo do homem, perante os acontecimentos que o cerca. A personagem central tem a necessidade de produzir ou criar, para escapar da cristalização de imobilidade e da estagnação que o cerceia.

Logo numa segunda-feira, no período do que ele chama de "nascimento", ainda desorientado sobre como agir nessa falta de fluxo que o repele ao descontentamento, fica à espera de agir. Nesse novo nascimento, renascimento, Carlos tenta dar vida à sua vida morta. Mas não escapa. Continua preso às amarras de uma "verdade" que já não é mais a mesma. No entanto, a esperança bate à sua porta, na figura de uma mulher: a Pintora que entra em sua morada, porém restrita e comandada por ELE.

Poderíamos aludir esse "renascimento" ao Renascimento que Wagner (2000) aponta, quando diz que não haveria como fazer renascer uma arte grega "perfeita", de uma sociedade relativamente livre (já que havia a relação entre senhor e escravo), em seus dias atuais. A Pintora, escravizada pelo seu senhor, e aqui num diferente contexto político-social que a da tragédia grega, não poderia reflorescer: era preciso que se florescesse uma nova forma que não reproduzisse o erro da arte grega, em que apenas os "belos" (os helênicos genuínos) pudessem representar a arte pura da qual os "bárbaros"(os miscigenados) eram proibidos de participar, ainda que servissem de suporte para sua realização.

Ainda, considerando a tentativa de ruptura com quaisquer influências de outras artes antepassadas, para a criação de uma nova arte e a liberdade de exercê-la, Artaud (1983) elucida que as obras-primas anteriores servem apenas como referência para o período em que foram criadas, e não para a "sociedade atual"3, que tem o direito de

\footnotetext{
${ }^{3}$ Nesse caso, a "sociedade atual" destacada refere-se aos homens da época de Luiz Castro, na composição de sua peça, cujos personagens estão a ser analisados.
} 
apropriar-se aos modos de sentir de sua época. O mesmo autor, ainda, expressa que arte (nomeadamente o teatro) deveria ganhar nova forma, ruindo com as enganosas e falsas ilusões a que ele se predestinava, de cunho extremamente literário a que o público não poderia ter acesso, oriundos desde a arte da Renascença.

Numa analogia entre a personagem Pintora e a Arte, em $A$ Semana, ELE seria associado a Salazar, o repressor e a ditadura. No primeiro momento, por detrás de seu cavalete estático, cujos desenham reproduziam imagens comandadas por seu senhor, a Pintora não possuía a liberdade da qual a arte necessita para captar os sentimentos humanos que ela busca sublimar. O homem, Carlos, embora procurasse na arte uma maneira de expressar-se e reconhecer-se, era incapaz de aceitá-la, pois naquela dita(dura) não podia reconhecer-se. Buscava encontrar um trampolim para seus impulsos e mergulhar em suas emoções, mas não conseguia aceitar o tipo de arte que lhe impunham:

PINTORA - Agradecia que se sentasse ali mais para a direita e olhasse para a janela...vai demorar algumas horas...procure uma posição cômoda...

CARLOS - Sentado comodamente num dias destes? Impossível! A senhora tem que olhar para mim e fazer o que quiser com os meus movimentos, tem que dar ao seu quadro a vida nova que eu hoje tenho, a força dos meus braços, a certeza do meu olhar, a temperatura ansiosa dos meus pensamentos! O seu quadro só assim significará alguma coisa. Eu esqueço-me de si e a pintora pinta! (Castro, 2006: 39).

Carlos pede mais poesia na pintura e menos palavra na poesia, como aponta Deleuze e Guattari (1992). Pede para que o pinte do jeito que estivesse, para dar vida ao quadro feito, e para que o pintasse como a pintora se sentisse. Ainda que se sentisse o vazio do homem, no tudo indefinido (nada), era por via desse vazio que se poderia preencher a tela com a mais bela das artes. Delleuze e Guattari (1992: 215), diz o sobre o vazio necessário a uma pintura, com bolsões de ar, que infla e encolhe, como num processo respiratório para sua perpetuação, que "o vazio é uma sensação, toda sensação se compõe com o vazio, compondo-se consigo (...) se conserva no vazio conservando-se a si mesmo".

Não obstante, a Pintora, assim como a Arte, retornaria forte e assoladora nos dois dias posteriores, após ter respiro, ao romper e "matar" dentro si, o mal que a assombrava, o sufocante ELE. Nessa perspectiva, a Arte seria também a Revolução dela própria, que tolhida, revolta-se e age em prol de sua libertação, revolucionando sua própria arte, modernizando-se.

CARLOS (Tirando a tela do cavalete.) - Porque ele restringe a sua arte...não lhe dá a liberdade de expressão....mas!...a tela está toda preta! Isto não é o meu retrato!

PINTORA - (...) sabe, eu nunca olhei para nada nem para ninguém vivo em toda a minha vida, por causa dele. O que eu sempre fiz foi pintar como ele dizia que devia ser, 
enquanto eu imaginava outras coisas...com seria a vida e o amor...mas que nunca era...o que pintei aí, agora livremente, não passa da materialização do imaterial...o que fiz não foi senão concluir o que estava feito desde há muito... Eu nunca olhara para ninguém vivo antes (...)

CARLOS - Então ele morreu...

PINTORA - Matei-o. (Castro, 2006: 39)

Metaforizada como a Revolução da Arte, a Pintora pode ser entendida como aquela que traz promessas de dias mais promissores, um futur(o)ismo surrealista pósmoderno, mas que só pode ser concretizada mediante a ação do homem, encarnado no desiludido e atormentado Carlos, espelhado na duplicidade de seu criador Luiz de Castro. Expressões temporais como "agora", "antes", "cedo", “ontem", daqui a pouco", "sempre", "até acabar", "sem nunca ter fim", “amanhã”, "tantos anos”, “todos os dias", primeira vez", "tarde", "hoje”, "vem aí”, torna o leitor mais atento à apreensão de que os esforços são necessários para a transformação, por meio do que foi ontem, chegando ao hoje para um respiro da espera e do vazio, e potencializando-o para um novo fazer do amanhã. O caos instala-se, agride o homem, mas também o liberta, e para Artaud (2012: 89)

O esforço é uma crueldade, a existência pelo esforço é uma crueldade. Saindo de seu repouso e se distendendo até o ser, Brahma sofre, talvez de um sofrimento que fornece harmônicos de alegria, mas que, na última extremidade da curva, só se expressa por uma terrível trituração.

Ela esteve lá, a todo momento, à espera de sua descoberta. A Pintora-ArteRevolução, após exaustivas tentativas a pairar sobre o homem (na cegueira de sua própria existência), rebela-se novamente e surge como Revelação. Incessantemente esteve ao lado de seu criador, do homem que criou sua existência; o autor pródigo que, paradoxalmente, esqueceu de revelá-la para si: “(...) a felicidade nem todos veem à primeira ou segunda vista..." (Castro, 2006: 54-58). E antes que perdesse a essência de sua própria virtude, a agora Pintora-Arte-Revolução-Revelação permite-se ser vista pelo Inspetor, este que à busca da "tinta vermelha", desnuda-a e a exime. A Rev-lução/Revlação, assim como o amor que dela expela, também exaure-se. Deixa de acontecer por já ter acontecido: “(...) já não me pertenço. Revelei-me e a felicidade ao revelar-se deixa de se possuir" (Castro, 2006: 61). Porque o amor é construído senão com luta e

Só os homens dotados de força conhecem o amor, só o amor apreende a beleza e só a beleza dá forma à arte. (...) Chegará o dia em que os homens, através da liberdade, serão dotados da mesma força, através da sua força, capazes do verdadeiro amor, e através desse amor, detentores da beleza. E a arte é a beleza em atividade (WAGNER, 2000: 93-94). 
O sangue da revolução é, então, derramado. Como de uma taça distraída e voluntariamente derrubada, espalha-se e se perde novamente, sem nunca manchar o que poderia renovar, dar lugar ao realmente novo. E se o homem não pode agir sozinho, também não pode esperar que a Pintora-Arte-Revolução-Revelação "bata atrás de uma porta" que a espere agir por si só. E na caminhada dos contras, a arte é pioneira em desafiar-nos, tornando o material em imaterial, com e no outro. A Pintora aparece, mas também foge quando o tempo é alvo para sua servidão, apreensão ou seu extermínio:

E como podem os homens ter esperança de se tornarem livres e autossuficientes, se não puderem exercer em liberdade a sua atividade mais nobre, a atividade artística? (...) comecemos então com a tarefa de libertação da arte pública, porque ela é o que há de mais elevado e lhe está reservado o papel de extrema importância de movimento social dos nossos dias (WAGNER, 2000: 104).

\section{REFERÊNCIAS}

ARTAUD, A. (1983). Acabar com as obras-primas. In: C. Willer (Org.). Escritos de Antonin Artaud, pp. 15-19. Porto Alegre: L\&PM.

ARTAUD, A. (2012). Teatro e seu Duplo. São Paulo: Martins Fontes.

CASTRO, E. M. M. (2006). Teatro do Homem (L)ido. Metaficção Crítica e Teatral, 1954 - 2000. Lisboa: Publicações Dom Quixote.

DELEUZE, G. \& GUATTARI, F. (1992). O que é a filosofia? (B. Prado Jr \& A. A. Muñez, Trads). São Paulo: Ed. 34.

NIETZSCHE, F. (2005). A Gaia Ciência. São Paulo: Editora Rideel.

WAGNER, R. (2000). A Arte e a Revolução. (J. M. Justo, Trad.). Lisboa: Antígona.

Recebido 05/04/2019

Aprovado 11/12/2019 